\title{
INCREASING THE QUALITY OF AGRICULTURAL MACHINERY TESTING - A COMPARISON BETWEEN ITALIAN AND POLISH EXPERIENCE
}

\author{
Agnieszka Klembalska ${ }^{1}$, Giulio Fancello ${ }^{2}$ \\ ${ }^{1}$ Industrial Institute of Agricultural Engineering, Poland \\ 2 European Network for Testing of Agricultural Machines, Italy \\ Corresponding author: \\ Agnieszka Klembalska \\ Industrial Institute of Agricultural Engineering \\ Department of Marketing, Standardization and International Cooperation \\ Starolęcka 31, 60-963 Poznań, Poland \\ phone: (+48)61 8712266 \\ e-mail: agnes@pimr.eu
}

Received: 10 April 2015 Accepted: 5 May 2015

\begin{abstract}
Safety of agricultural machinery is a key aspect in carrying out agrotechnical treatments Appropriate testing of machines and equipment guarantees better protection of life or health Applicable conformity assessment procedures do not require (except for particularly dangerous machines) participation of the third party - a professional, specialized, accredited, notified testing laboratory what raises a common fear of the dangers arising from ignorance of manufacturers.
\end{abstract}

KEYWORDS

agriculture, laboratory, safety, standards, tests.

\section{Introduction}

European Union regulations on approval of the product on the market require a great deal of experience and knowledge of the issues of standardization. In practice, there are many cases of designing the agricultural machines without taking into account the requirements of the directives and harmonized standards and then their production and marketing without conformity assessment. It is necessary to raise the awareness continuously among designers and manufacturers of agricultural machinery as well as dissemination of information on conformity assessment system, the obligations of the manufacturer and substantive knowledge of the requirements for the safe and efficient farm machinery. Manufacturers guided only by the financial criterion use the possibility of self-made estimation of the risks, do realize entirely of the benefits which imply providing the machinery to specialized laboratory.

The quality in the context of use of agricultural machinery is described mainly by two concepts
- safety and ergonomics. Both these aspects are testable, there is a number of indicators (including, covered by regulations and standards) which define their level, and thus - an indication of whether the machine can be approved for use.

\section{The situation in agriculture in terms of accidents}

There is no doubt that the issues related to the safety of use of agricultural machinery are extremely complex. Safety issues are dealt with for the entire life cycle of a technical object. Agriculture in terms of the scale of the accident at work is one of the most dangerous sectors of national economy of Poland and Italy. It consists of a number of reasons, among which there are as follows:

- a large number of types of machinery and equipment used in agriculture, estimated at more than 800 , different in terms of the complexity of the structure [1]; 
- large difference in the purpose of use of each type of machinery (from simple single-purpose to complex function processes);

- diversity and high variability of environmental conditions of use;

- a full scope of risks associated with the appropriate machines and conditions of use (physical, chemical and biological hazards);

- diversity of users of machinery and equipment, both in terms of qualifications, education, and the level of technical culture, age (machinery are also used by family members, including children).

Moreover, the specific socio-economic situation of Polish agriculture implies additional risks that occur much less frequently in Italy. Italy as a founding member of the EU for many years has a normalized situation in agriculture, both legally and economically. The Land Reform Acts of 1950 entailed the redistribution of large tracts of land among the landless peasantry, thereby absorbing greater amounts of labour and encouraging more efficient land use.

In the structure of Polish agriculture selfsufficient type of agriculture prevails family farm, which means that the farmer undertakes to work in many specializations; a multitude of different activities - is a minimal chance to become proficient in their implementing. Polish agriculture is in a difficult financial situation as a result of which it does not regenerate a sufficient degree of technical equipment, and used old machines often represent a hazard by high unreliability, lack of security, etc. This situation is also the reason for farmers to buy a cheap second-hand equipment, as well as the use of machinery, equipment and tractors without any protection, most often made completely unprofessionally by the farmers themselves. Difficult financial situation of Polish industry does not encourage manufacturers to conduct research and development, introduce new safer designs and voluntary testing, eg. maintenance testing, which could be a source of information about the functional defects or reliability of machines and about a different, often inappropriate behavior of users in response to these disadvantages. The structure of the impact of various sources of safety unreliability on accidents is similar annually. In individual agriculture, generally accidents caused by the collapse of people prevail (average about $50 \%$ of cases) catching or hitting the moving parts of machines (average of about $13 \%$ of cases), as well as hit, bitten or crushed by livestock (average of about $10 \%$ of cases) [2]. Based on the results of tests held in the Testing Laboratory of Agricultural Machines of Industrial Institute of Agricultural Engineering (PIMR) it can be observed that most of the hazards occur in the use and maintenance of machines of the following groups:
- machines for sowing and planting,

- machines for fertilization and plant protection,

- machines for farms and livestock,

- machines for soil cultivation,

- root crops harvesting equipment,

- machines for cereals, greens and hay harvesting.

\section{EU regulations in the field of agricultural machinery testing}

The main objective of European legislation in the area of agricultural machinery testing is the safety of people and the environment. Conformity assessment system, valid in the European Union is governed by thirty eight directives that have been implemented into Polish law by the Act of 30 August 2002 on conformity assessment system [3]. The European Union has a system of technical harmonization of law, which allows for the movement of goods in conformity with the essential and other safety requirements. Directives of technical harmonization contain provisions for placing on the market the products and permitting them to be used, free movement, the principles of recognition of compliance, conformity assessment procedures, notified bodies, CE marking, coordination of implementation and transposition into national legislation and essential requirements for safety and health protection. A precondition for placing the product on the EU market (regardless of country of origin) is:

- assessment of conformity of the product with the relevant directives (directive) by the manufacturer (supplier), or - in the case of particularly dangerous products - by a third party (authorized notified body),

- issuance by the manufacturer (supplier) a declaration of conformity, confirming that the product complies with the requirements of the relevant directives (directive), and optionally with the requirements of harmonized standards under the directive concerned,

- CE (abbreviation of Conformité Européenne) mark product identification.

The manufacturer (supplier) must on his own responsibility assess whether the product subject to only one directive or more. In case if the product is covered by several directives, it must meet the requirements of all relevant directives. In the case of machinery, the relevant directive is called Machinery Directive 2006/42/EC [4], and often Low Voltage Directive 2006/95/EC [5], the Electromagnetic Compatibility Directive 2004/108/EC [6], and one of the ten directives concerning noise. Since the directives formulate only the essential technical 


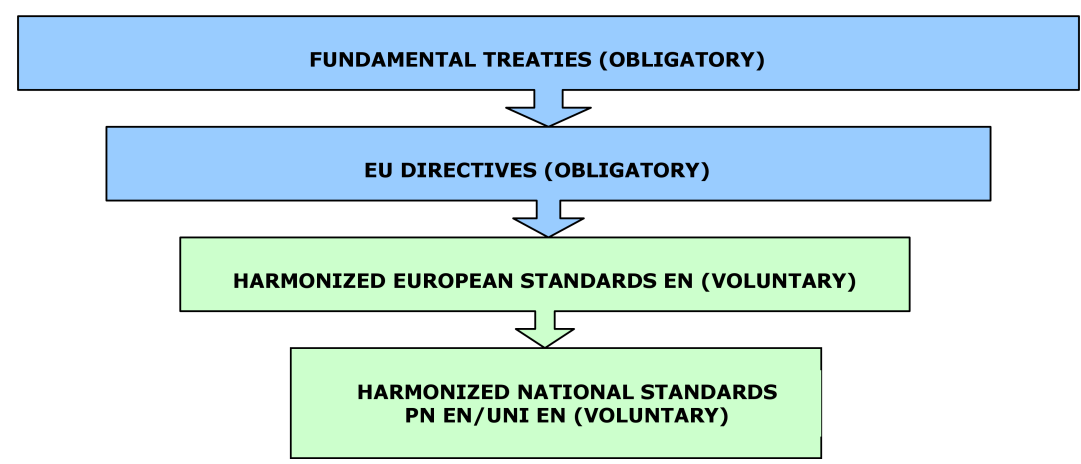

Fig. 1. Structure of the EU legal acts. Source: own work.

requirements, conformity assessment should consider in addition more particular requirements referred to in European standards harmonized with the directive concerned. European standards are not mandatory, but their use is recommended, since they allow standardize requirements and their compliance can be assumed that the product is also in compliance with the essential requirements of the directive (the principle of presumption of conformity). For harmonized standards there are considered European standards (EN), published in the Official Journal of the European Communities, which distinguishes between three types of standards:

- type A standards (basic safety standards),

- type B standards (safety of certain groups of machinery and equipment), which deal with one aspect of the security (eg. safe distance, noise) or one type of safety devices common to many machines or devices,

- type C standards (safety of machines), with specific safety requirements for specific machines or groups.

As mentioned above, the process of product conformity assessment can be carried out directly by the first (manufacturer, supplier) or by a third party (notified body). Individual technical harmonization directive gives the manufacturer a choice of appropriate conformity assessment procedure, according to certain modules, depending on whether the product has been recognized in the directive to be particularly dangerous, the phase in which the product occurs (design or production) and whether the design (production) conforms the standards. It is not always so that the manufacturer must outsource it to the third party. Generally, all the possible procedures and conformity assessment modules (eight basic modules and eight of their variants), together with the basic guidelines of the application are described in the European Union Council Decision 93/465/EC [7]. Assessment of conformity by the said Decision should be based alternatively on:
- Module A - Internal production control,

- Module B - EC type-examination,

- Module C - Conformity to type,

- Module D - Production quality assurance,

- Module E - Product quality assurance,

- Module F - Product verification,

- Module G - Unit verification,

- Module H - Full quality assurance,

or using variants of the above modules. For example, the Machinery Directive allows to the use of three modules: A, B, and C.

Extremely important legal regulations of the European market of safety are two more directives:

- Directive 85/374/EEC on liability for defective products [8], allowing to enforce of defective product liability, defining the responsibility of the manufacturer, importer and seller for damages caused by defect of the product, as well as the rights and obligations of the injured person; the directive also defines the terms: product, defective product, manufacturer, importer, supplier (seller), the injury;

- Directive 2001/95/EC on general product safety [9], requiring manufacturers (and retailers) to market only safe products and to provide consumers with adequate information to enable them to assess the risks and taking appropriate precautions against risks; the directive also requires manufacturers (and retailers) to collect information about the possible risks associated with their products and to take appropriate action to avoid the hazards causing by the product (including the withdrawal of the product from the market if necessary); it also provides definitions of the terms: safe product and unsafe product and establishes the procedures of state supervision over the safety of the products.

The development of technology and economy causes that a man seeks to improve the machinery, in order to achieve the objective with minimal manual effort and financial costs as well as the highest quali- 
ty. With the development of mechanization processes the attention should be paid to the safety of an individual person. This problem is governed by the new approach directives that precisely define the essential requirements to be met in order to place the product on the market or to put into operation. The easiest way to demonstrate that the product complies with the essential requirements is to use the harmonized standards under the directive concerned. A manufacturer who complied with the essential requirements is satisfied that made every effort to ensure that the product was safe for the user.

The directives adopted by the European Parliament are the main element of the system of technical legal harmonization. In order to avoid discrepancies in the interpretation of the essential requirements of the new approach directives (through the formulation of specific requirements) and the reliability of evaluation (by specifying the test methods and criteria for evaluation of the results of tests), the legislature introduced the concept of an EU harmonized standards with each new approach directives. The application of these standards is voluntary, but in the quickest and easiest way allows to prove whether the product complies with the essential requirements. The principle of the presumption of conformity applies, according to which the product produced in accordance with the harmonized standards of the directive concerned, meets the essential requirements of the directive.

Standardization activities generally aims to obtain the optimum degree of order in the given circumstances. In particular standardization contributes to the rationalization of production and services, the removal of technical barriers in trading, ensuring the protection of life, health, environment and consumer interests and safety at work, improve the functionality, compatibility and interchangeability of products, processes and services and the regulation of their diversity, assurance of quality and reliability of products, processes and services, facilitating communication by defining terms, definitions, signs and symbols into common use, preservation of the achievements of technology.

\section{Aspects of testing of agricultural machinery in Italian and Polish legislation before and after 2004}

Italy by virtue of being a member of the EU since the inception of this international organization is required to apply the CE marking, mandatory in the European Economic Area since 1985. The CE marking is a symbol of free marketability in the Euro- pean Economic Area (Internal Market). The whole system of safety testing and conformity assessment and machine approval conditions onto the market is, therefore, since 1985, the same as in Poland after EU accession.

Before Poland EU access, a safety certificate entitles the producer to the marking of the product by "B" safety mark was a confirmation that the product is safe.

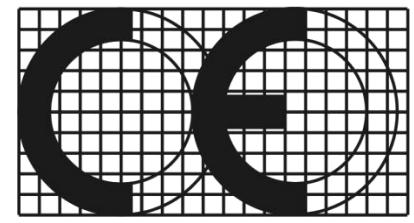

Fig. 2. CE marking model. Source [3].

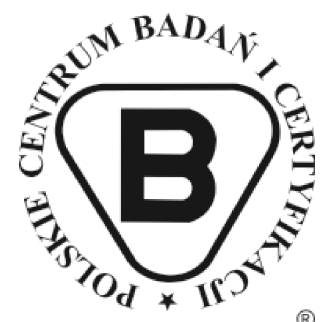

Fig. 3. "B" safety mark. Source [13].

Such a mandatory labeling referred to the products defined in appropriate regulations, and compliance verification with the safety requirements in accordance with the Act on testing and certification [11] was made in the certification process by independent of the manufacturer and the user, the certification bodies accredited by the Polish Centre for Accreditation. Under this Act, a product manufactured in Poland or article imported into Polish for the first time, potentially hazardous or serving the protection or saving life, health and the environment was, depending on the degree of risk must have:

- been subjected to obligatory certification for "B" safety mark and marked with this symbol,

- hold issued the declaration of conformity of the product with the relevant safety requirements by the manufacturer on his sole responsibility.

For nearly 15 years the validity the "B" mark has gained many supporters - mostly customers or users of products, but also many manufacturers. After the Polish UE accession sign the "B" certificate has ceased to be a document that allows the introduction of products on the market. Polish list of products subject to third-party certification included much more products than the corresponding list in Annex IV of the Machinery Directive [4]. For example, most types of agricultural machinery were subject to compulsory certification. This obligation was 
translated directly to the number of orders for certification testing in accredited laboratories for agricultural testing. This situation is illustrated in the chart below. The example of the Testing Laboratory for Agricultural Machines of Industrial Institute of Agricultural Engineering (PIMR) shows how varied the number of orders for tests from producers, depending on their status (obligatory/voluntary). The number of orders for obligatory testing ("B" safety mark 2001-2003) remained relatively constant (and high) level of about 70 per year. In 2004, those orders were replaced by orders for safety tests and documentation development for conformity assessment, which is the basis to issue a declaration of conformity and marking of machinery CE mark. It was due to the fact of adoption of the EU system. Although the obligation to carry out these procedures of outsourcing it to the third party was practically abolished, designers and manufacturers of agricultural machinery were not adequately prepared to carry out the hazard analysis that cause the machine during use - in the absence of the transitional period, the choice of an accredited laboratory has become the safe solution. Over time (already in subsequent years), number of orders for this type of tests drastically decreased (approx. 90\% compared to the record 2004), and remains at a low level. The Testing Laboratory of Institute of Technology and Life Sciences in Warsaw carries out only several tests for "B" safety mark annually - these are sporadic cases when the manufacturer needs a certificate for marketing purposes (e.g. for export to the East).
Polish National Labour Inspectorate conducts inspection of machinery and equipment for safety. In the years 2006-2010 in the course of routine inspections and testing of complaints, labor inspectors checked the machines and equipment in number of 2770 , questioning the machines in number of 1190 (43\%) [13]. These figures show that in Poland, producers or companies marketing the products imported from countries outside the European Union do not realize the seriousness of the situation, that a issued declaration brings with it a great responsibility. If as the result of the inspection, the situation that conformity assessment documentation is not consistent with the facts arises, the producer is penalized. In such a situation, it is very important who performed the test. If the tests were made in the company, the manufacturer shall be liable for his employee. If, however, the test was outsource to a accredited or notified body, the manufacturer has the right to apply in relation to the laboratory reimbursement claim they suffered due to incorrectly tests.

Effective impact on the safety of use of agricultural machinery requires a change in approach to shaping the safety, from the planning stage (modernization) to ending stage of testing. Note that the CE is not:

- a safety certificate,

- a trademark,

- an indication of origin,

- a quality mark,

- a mark of compliance with the standard.

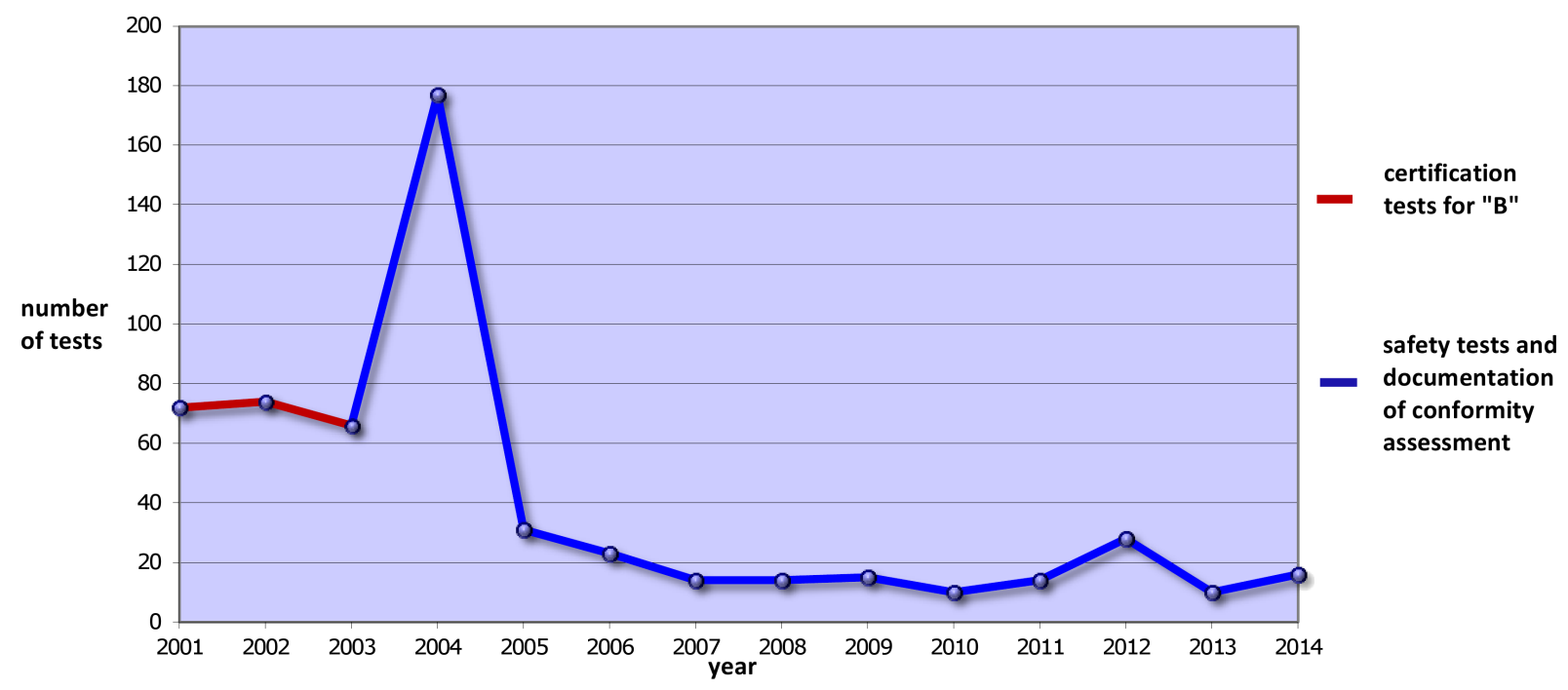

Fig. 4. A number of certification test for "B" safety mark and safety tests and documentation of conformity assessment developed in Testing Laboratory for Agricutural Machines of PIMR from 2001 to 2014. Source: Own work on the basis of [12]. 


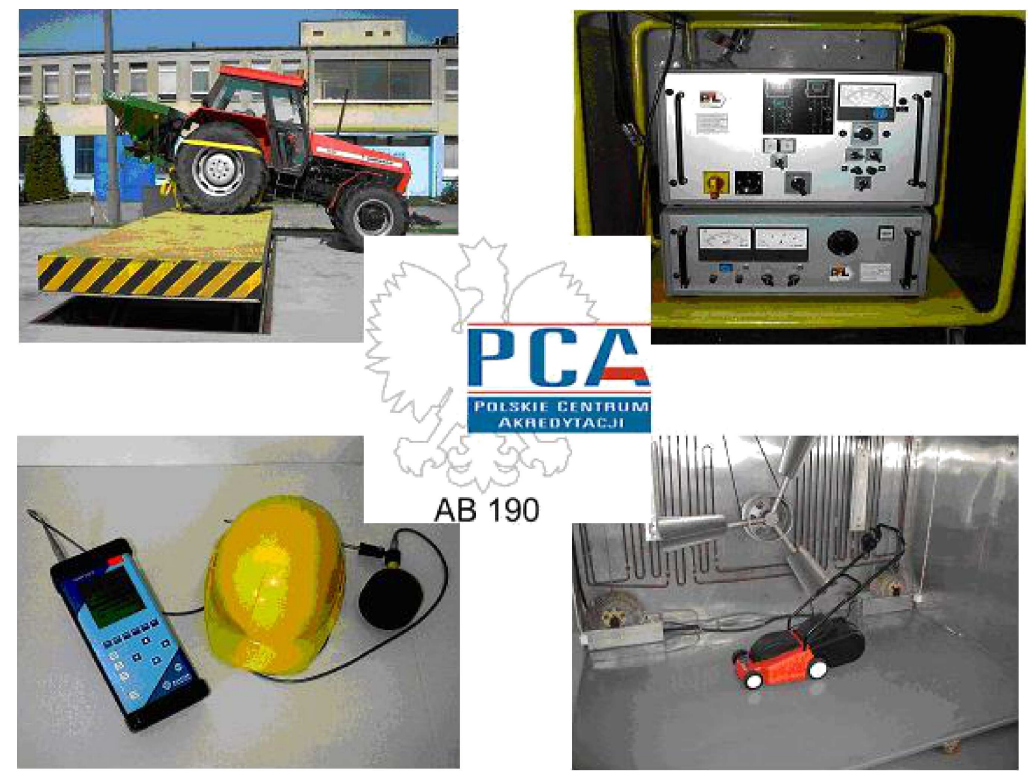

Fig. 5. Examples of testing stands in Testing Laboratory for Agricultural Machines of PIMR.

\section{Polish and Italian common certification activities - the ENTAM network}

The increasing globalization of markets is leading to a greater request for the standardization of processes for protection of people and the environment in relation to the use of mechanical equipments.

The purpose of European and international standards is to bring about criteria for evaluation which are as alike as possible. Over the time, these norms have been developed by ISO, International Organization for Standardization, and CEN, European Committee for Standardization, through their Technical Committees. Though these standards establish fundamental criteria, they must often be interpreted for achieving precise tests which are comparable one against the others and provide an optimum evaluation of the performance of machinery. Moreover, to reach a reliable level of machinery testing highly specialized test centers must be turned to [14]. For the above mentioned reasons, a number of European testing centers decided in 1999 to sign a cooperation agreement which gave rise to ENTAM, European Network for Testing of Agricultural Machines. ENTAM is based on an agreement among testing centers which are officially recognized in various European countries and the purpose of the network is to standardize testing for evaluating the performance, safety and environmental aspects of agricultural machinery. The tests, carried out in specialized ENTAM testing centers on the request of the manufactur- er, are based on national, European or international standards and shared agreements or methodologies. The testing activity output is a test report which summarizes the technical data measured by the experts according the testing methodologies. The test report is submitted to the other ENTAM members for their evaluation and, finally, it is "ENTAM recognized" which means that all the ENTAM Members acknowledge that the machine tested fulfil the European or international standards. At the end, there are several beneficiaries of the ENTAM recognition: the manufacturer getting valuable information from testing activity improving the machine quality; the end-users making the best choice when purchasing the tested machines.

The ENTAM network has become a valid instrument as a marketing tool for those manufacturers who sell "ENTAM recognized" machines, they gain visibility on foreign markets thanks to the ENTAM logo and the reputation of the ENTAM Members, internationally recognized institutions such as:

- Francisco Josephinum BLT in Austria,

- Institut National de Recherche en Sciences et Technologies pour L'environnement et L'agriculture (IRSTEA) in France,

- Julius Kühn-Institut (JKI), Deutsche Landwirtschafts-Gesellschaft e.V. (DLG), Kuratorium für Waldarbeit und Forsttechnik (KWF) in Germany,

- National Agricultural Research Foundation (N.AG.RE.F) in Greece,

- Mezogazdasági Gépesítési Intézet (MGI) in Hungary, 
- Ente Nazionale per la Meccanizzazione Agricola (ENAMA) in Italy,

- Przemysłowy Instytut Maszyn Rolniczych (PIMR) in Poland (since 2001),

- Centre de Mecanització Agrària (CMA) and the Estación de Mecánica Agrícola (EMA) in Spain.

Beside the manufacturers and end-users, also the policy makers may benefit from the ENTAM network activities getting, for example, a decision support system in providing incentives for the agricultural machines market. Incentives for purchasing of machines which have the ENTAM recognition may be funded thanks to their higher performance and safety standards. In Italy the ENAMA in cooperation with the Ministry of Agriculture has carried out a study investigating the incentives for certified machinery provided in the 2007-2013 Rural Development Programme (funded by the EU); a certain number of Regions provided incentives for the purchase of machines with a safety or performance certification. We can imagine that this trend may raise significantly in the next 2014-2020 Rural Development Programme. One of the leading issue, among the ENTAM working groups, is the need to identify new testing standards for the environmental performance of the agricultural machinery and equipment. The ENAMA is an Italian accredited association recognised in accordance with the provisions of Italian Presidential Decree n. $361 / 2000$, its aim is to offer the agromechanical industry in Italy in order to improve competitiveness, enhance technology and raise awareness of the performance and safety features of the machinery amongst the stake holder of the agricultural sector.

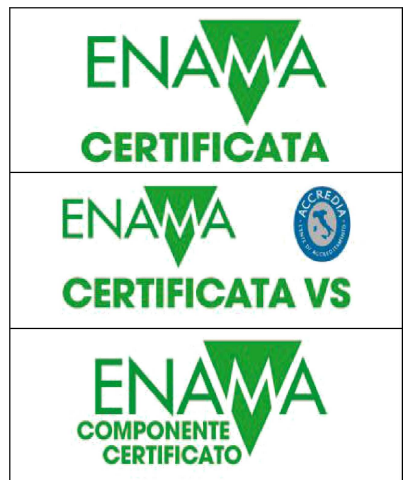

Fig. 6. Marking of ENAMA certification. Source [15].

The following parties are represented in the ENAMA's board: the Italian Ministry of Agriculture and Forestry, the Italian Regional Authorities, the main professional agricultural organizations: Assocap, Cia, Coldiretti, Confagricoltura, Unacma, Unacoma and Unima. The operational structure is constituted by
CRA-ING, the Council for Research and Development in Agriculture. The machinery test - based on the existing national and international (ISO, $\mathrm{EN}$, etc.) regulatory frameworks - are conducted in specialised testing centres that are co-ordinated by ENAMA. The results of these checks are published in special test certificates and reports that contain all the information on the agricultural machinery tested, constituting an effective sort of identity card that accompanies the machines throughout their lifetimes. The following officially certified data is shown on the machine's certificate:

- description,

- accessories (if applicable),

- technical specification of the machine,

- test conditions,

- performance,

- test results,

- comment on functionality,

- indications for appropriate use in road traffic,

- conformity with existing safety regulations,

- other models of the same series (if applicable).

The safety aspects are particularly important given that a certified machine fulfils the basic condition for conformity with the provisions of Italian Presidential Decree 459/96, which encompasses the Directive on Machinery, Italian Legislative Decrees $359 / 1999$ and 81/2008 and all other relevant regulations.

Since 2005, manufacturers of agricultural machinery have been able to choose between full certification of the functionality and safety of their machines (ENAMA certification) or partial certification, focusing only on the safety aspects (ENAMA VS certification). The VS option offers lower costs and reduced times compared to full "ENAMA Certification", but provides the same level of guarantees in relation to the safety specifications.

If the machine passes the relevant tests, the manufacturer is issued with "ENAMA VS Certification" in recognition of the excellence of that model. As a voluntary certification, ENAMA VS functions alongside the CE mark (without substituting it) and gives the machine added value in that it has been approved by a third-party body. "VS ENAMA Certification" is valid for five years from the date of issue, except when variations are made to those regulations that apply to the tested model or when there are changes to the design and/or construction of the standard model that make it different from the tested model. The manufacturer may apply the VS mark or display the proof of certification, for all machines that conform to the certified model. The mark may not be applied to machines that do not conform to the cer- 
tified model(s). In short, the new service provides the manufacturer, the dealer and the user with a guarantee that the machine conforms to the specific safety regulations applicable to it. ENAMA is promoting internationally a series of initiatives aimed at building up a European-wide voluntary certification system for the industry that covers, above all, those aspects that relate to the safety of agricultural machinery.

During the certification process, the machine undergoes specific tests. If it successfully passes these tests, the machine is awarded an officially recognised certification mark. ENAMA-certified machines are given privileged access at national and international trade shows. Since 2002, a certification service for agricultural machinery components has been available. The following officially certified data relating to the components is shown on the certificate:

- technical specification of the component,

- description,

- test methodology,

- test results,

- comment on functionality.

There are many advantages of the certification:

- for manufacturers: over recent years in Italy, several regulations have come into force that rule the performance and safety of agricultural machines. The most important is the Legislative Decree ("decreto legislativo") no. 81/2008 aimed to improving health and safety in the workplace, and the Machinery Directive 2006/42/CE. These regulations ensure that only agricultural machines fulfilling all the safety regulations currently in force are released onto the market. Given this context, the advantages of ENAMA certification are as follows: guarantee and protection for the manufacturer since all of the regulations have been met and officially certified as such, providing certainty that the agricultural machinery being released onto the market conforms to legal requirements, further proof of the quality of the machinery and of its effective functionality, recognition in other European countries thanks to the agreement with those countries;

- for dealers: current Italian legislation prescribes that only machines that fulfil all the existing safety criteria be released onto the market. Given this context, the advantages of ENAMA certification are as follows: guarantee and protection for the dealer that the agricultural machinery being released onto the market conforms to legal requirements, ensuring that the product supplied comes complete with all the necessary information for its correct use;
- for farmers: current Italian legislation prescribes that the manager of the agricultural company is responsible for ensuring that the agricultural machinery is properly equipped and is being used correctly. Given this context, the advantages of ENAMA certification are as follows: guarantee and protection of purchasing a machine that conforms to regulations governing direct use by the manager and use by the company's employees, makes it easier to select the most appropriate machinery for the company's specific requirements by consulting and comparing the salient test results of each available machine.

Approval is the final stage in certifying that a given vehicle, component or technical device conforms to the technical criteria imposed by the relevant regulations in order, principally, to guarantee road traffic safety. Approvals are either nationwide or Europe-wide. The relevant regulations prescribe precise criteria in relation to the construction of the machinery and the different features that it is required to have. For some considerable time, ENAMA has been taking a pro-active role in promoting the correct planning and execution of the approval process and has taken on institutional roles on various industry-based commissions both in Italy and internationally. ENAMA currently provides support for the following types of approval processes:

- national approvals are valid only in the country where the certificate of approval is issued. In Italy, the legislature has prescribed certain derogations and procedures that may be used as alternatives to national approval: limited approval for small batches: where the limited number of machines is sufficient to justify (technically and financially) the omission of certain tests (for farm machinery: 250 units per calendar year per type), temporary approval: when the requested derogation, in relation to vehicles, is deemed necessary for experimental reasons. Vehicles that have achieved EU approval are, however, required to undergo further national tests and checks in order to ensure road traffic safety. This operation is referred to as "transfer of EU approval";

- OECD (Organisation for Economic Co-operation and Development) approval of farm and forestry tractors is based on a regulatory framework (OECD Codes) that prescribes specific tests and provides useful criteria for evaluating the performance of tractors and associated protective structures.

- EU approval - crucial for the release onto the market of farm and forestry tractors - can concern either the tractor as a whole (type approval) or 
its components (partial approval). The regulations relating to partial or type EU approval are shown in the particular directives. The new 2003/37/CE Directive, the framework for CE approval, defines the possibility of using the following as alternatives to the particular directives: the basic directives for motor vehicles; the UNECE regulations; the OECD codes. Directive 2003/37/CE also prescribes extra categories of vehicles for which there are currently no particular directives and which are not, as such, currently subject to EU approval. Vehicles that have achieved EU approval are however required to undergo further tests and checksin order to ensure road traffic safety. This operation is referred to as "transfer of EU approval".

Since October 2009, in fact, two new European Directives have been issued for crop protection machinery and equipment. In detail, Directive 2009/128/EU provides a common framework for the sustainable use of pesticides whereas the Directive which modifies the machinery directive introduces harmonized regulations on marketing crop protection machinery and equipment in all the member states of the European Union. The member states must, therefore, require the compliance of all brand new machinery with the important new crop protection standards. The manufacturers may carry out themselves the measurements of the doses of pesticides distributed, the amount of drift generated and the values of deposits on target etc. etc. or they can have these tests performed by an Institution which certify the compliance of the machinery or equipment before selling it in the market. The member states, and thus the manufacturers of sprayers and their components, must apply these regulations as of mid-December 2011. The ENTAM members are playing a major role, involving more and more manufacturers in the testing activities, and supporting the policy makers in the Directive implementation at national level. The goal of the ENTAM network, as an independent legal entity, should be to get involved in the Directive implementation at European level.

\section{Summary and conclusions}

The presented principles of conformity assessment of products applicable in the European Union, which allow manufacturers of products with relatively low risk for their users, to independently decide on the compatibility of these products with the essential requirements of safety and health protection contained in the technical harmonization directives or requirements of the relevant harmonized standards. Therefore, they allow manufacturers to introduce these products to the markets of the European Union, without any verification by the notified body. In Poland, until 2004, the system of certification for safety mark "B" covered a much wider range of requirements and rigorous testing before allowing the machine on the market and put into use.

For all the machines manufacturer or supplier (or a third party on its behalf) is required to assess the conformity of the product with the safety requirements, supported by risk analysis. There is a reason to fear that the producers are not prepared for it. Professionals in practice are aware that in order to effectively manage the safety, it is necessary to develop and implement the overall risk assessment methods - including hazard analysis for the different phases of the life cycle of an object - starting from concept through design, to issues related to the safe operation of the facility. There is noted a lack of implemented, while relatively easy to accomplish methods for safety analysis. There is emphasized the need to develop and bring to the practice of design, manufacturing and operational methods of formulation and technical objects safety control, based on qualitative and formal risk analysis. Developed and implemented safety control systems usually refer to objects or areas considered to be extremely important such as: state defense, aviation and rail transport. Standards and regulations on safety often contain very general or partial requirements, limited to single issues and parameters. Designers access (payable) to standards and regulations was severely restricted after the liquidation the centers of industry and company standards in Poland in 1993.

The issue of liability for product, potential consequences of safety failure is a serious problem. It should be subject to some obligatory procedures involving a specialized professional entity of testing of safety, hazard analysis and risk assessment. Annex IV of the machinery directive [3] contains a closed list of 23 so-called "particularly dangerous" machines for which there is an obligation to apply the procedure involving a third party. A practice shows that many other agricultural machines raise a number of serious risks for the operator - it is therefore debatable issue whether the list should be extended.

On the other hand, the statistics prove that in recent years number of accidents in agriculture has been gradually falling down $[16,17]$. It is certainly due to many reasons: the improvement of the quality and safety of agricultural machines in operation, the increased awareness and the level of technical competence of machine operators, the reduction of 
a number of farms and their technical modernization [18]. A safety in use of agricultural machinery, considered as a quality indicator in the EU countries is gradually increasing.

Outsourcing voluntary testing and various analyzes of machines (e.g. efficiency, durability, particular operating parameters) seems to be due only to manufacturer marketing reasons. Open EU market also in the agricultural machinery industry is a very competitive field - the fight for the customer is based in large part on the ability to demonstrate the high quality of the product. Every certificate attesting declared machine parameters, made by the independent professional body are a valuable asset. The victory in competitive battle is a strong factor in the decision of the manufacturer. From the point of view of accredited and notified laboratories, there should be taken advantage of this aspect of the marketing campaign, encouraging the client to take advantage of their specialized services. Certainly, the support of a high quality product by an independent, reputable institution is "only" the result of a general policy of testing activities in Poland and Italy - safety is always the overarching target.

In order to intensify efforts to disseminate the idea of testing of agricultural machines and equipment there was formed the ENTAM Association, bringing together testing institutions of the industry. The result of active participation PIMR in ENTAM works was the inclusion of the European System of Mutual Recognition of Tests. It means that the tests done by PIMR will be automatically acknowledged by institutes of ENTAM member states and will be respected in the European market. It is an additional factor of marketing for manufacturers of agricultural machinery, if they want to sell them on the open market of the EU.

Any action to raise awareness of the importance of security in the use of agricultural machinery is extremely important and desirable. In such legal circumstances, the role of the State is to pursue a policy of raising the importance of properly conducted safety studies, risk assessment and risk analysis of agricultural machinery among the producers and thus - concern for the safety of the machinery use. However, help from the EU legislative bodies is necessary to change the consciousness of the producers themselves to change the actual meaning of the signs, certificates and diplomas from promotional character to safety, ergonomics and reliability witness.

All bottom-up initiatives are not to be overestimated. There is a place to meet a mission of specialized institutes established among others for this purpose, equipped with the appropriate measuring equipment, expert software and most importantly - employing highly qualified and experienced professionals. The experience is compounded thanks to advanced co-operation of European institutes, interlaboratory testing, development of common methodologies of tests.

The optional tests cumulative added value for entrepreneurs; the institutes are prepared for the expert analysis - to make this idea it should be the subject of conferences, seminars, information campaigns. Research institutes in Poland were established as a scientific support to the industry - only the commitment of both parties with the support of state bodies will enable the effective implementation of the function.

\section{References}

[1] The Characteristics of Agricultural Holdings. Agricultural Census 2010, Central Statistical Office, Warsaw 2012.

[2] Statement of Office of Prevention and Rehabilitation of Agricultural Social Insurance Fund on accidents at work and occupational diseases of farmers in 2014, Warsaw 2015.

[3] Act of 30 August 2002 on conformity assessment system. Polish Journal of Law 2014 pos. 1645.

[4] Directive 2006/42/EC of the European Parliament and of the Council of 17 May 2006 on machinery, and amending Directive 95/16/EC (recast), OJ L 157, 09.06.2006.

[5] Directive 2006/95/EC of the European Parliament and of the Council of 12 December 2006 on the harmonization of the laws of Member States relating to electrical equipment designed for use within certain voltage limits, OJ L 374, 27.12.2006.

[6] Directive 2004/108/EC of the European Parliament and of the Council of 15 December 2004 on the approximation of the laws of the Member States relating to electromagnetic compatibility and repealing Directive 89/336/EEC OJ L 390, 31.12.2004.

[7] European Union Council Decision 93/465/EC concerning the modules for the various phases of the conformity assessment procedures and the rules for the affixing and use of the CE conformity marking, which are intended to be used in the technical harmonization directives OJ L 220, 30.08.1993.

[8] Council Directive 85/374/EEC of 25 July 1985 on the approximation of the laws, regulations and administrative provisions of the Member States concerning liability for defective products OJ L 210, 07.08.1985. 
[9] Directive 2001/95/EC of the European Parliament and of the Council of 3 December 2001 on general product safety OJ L 011, 15.01.2002.

[10] Act from 3 April 1993 on testing and certification. Polish Journal of Law 1993 No. 55 pos. 250.

[11] http://www.pcbc.gov.pl/pl/

[12] Registers of orders of Testing Laboratory for Agricultural Machines of PIMR of 2001-2014.

[13] http://www.pip.gov.pl/pl/

[14] Limongelli R., "Italian and European Certification Systems", Mondo Macchina/Machinery World Magazine, 5-6, Rome 2010.

[15] http://www.enama.it/it/index.php
[16] "Accidents at work and occupational diseases of farmers and Agricultural Social Insurance Fund prevention activities in 2013", Office of Prevention and Rehabilitation of Agricultural Social Insurance Fund, Warsaw 2014.

[17] "Accidents at work and occupational diseases of farmers and Agricultural Social Insurance Fund prevention activities in 2012", Office of Prevention and Rehabilitation of Agricultural Social Insurance Fund, Warsaw 2013.

[18] Radniecki J., "Standards as a tool to ensure the safety of agricultural and forestry machinery", "Standardization. Messages of Polish Committee for Standardization. Safety of Agricultural Machinery - special issue", Polish Committee for Standardization, Warsaw 2014. 